\title{
Application of a residential end-use model for estimating cold and hot water demand, wastewater flow and salinity
}

\author{
HE Jacobs ${ }^{1 *}$ and $\mathrm{J}$ Haarhoff ${ }^{2}$ \\ ${ }^{1}$ GLS, PO Box 814, Stellenbosch, 7599, South Africa \\ ${ }^{2}$ Department of Civil and Urban Engineering, Rand Afrikaans University, PO Box 524, Auckland Park 2006, South Africa
}

\begin{abstract}
The structure and data requirements of an end-use model for residential water demand and return flow are presented in a companion paper. This paper focuses on the practical application of the model. The model is first applied to confirm a few commonly observed water demand patterns: Seasonal variation in demand, the positive correlation between average annual daily water demand and stand size, and the increase in water demand, hot water demand and wastewater flow with an increase in household size. The convergence between the predicted model results and independently observed values by others encourages practical use of the model. Secondly, the effects of some specific water demand management measures are evaluated by adjusting selected model parameters. The measures include xeriscaping, the installation of dual-flush toilets and low-flow showerheads, pool ownership and pool cover use. The model provides a rapid means to obtain first estimates of the likely effects of different water demand management measures.
\end{abstract}

Keywords: water consumption - mathematical models, water salinisation, hot water supply

\section{Introduction}

An end-use model for water demand and sewer flow analysis is discussed in a companion paper (Jacobs and Haarhoff, 2004).

In this paper the authors demonstrate the practical application of the model. Some definitions, abbreviations and acronyms used in the companion paper are not repeated here, as they are common to both papers.

The residential end-use model (REUM) enables the analyst to estimate the indoor- and outdoor water demand, hot water demand, wastewater flow, and concentration of total dissolved solids (TDS) in the wastewater flow for an individual residential stand and a given set of input parameters. This makes the model unique although other end-use models have been developed, applied and studied in South Africa (Van Zyl et al., 2004) none combine these five components into one model.

In this paper REUM is verified by investigating the convergence between the predicted model results and independently observed values by others. The paper also illustrates how a few specific water demand management (WDM) measures could be evaluated in detail with the use of REUM.

\section{Factors influencing the model results}

Numerous factors influence the indoor and outdoor water demand, hot water demand, wastewater flow and salinity. In REUM provision is made for 79 parameters, each varying over 12 months, to completely describe these five components. Table 1 indicates those parameters that require adjustment in this present investigation. For a full list of model parameters, reference could be made to Jacobs and Haarhoff (2004). Some of these parameters are briefly discussed below.

* To whom all correspondence should be addressed.

面+2721 880-0388; fax:+2721 880-0389; e-mail: Heinz@GLS.co.za Received 12 January 2004; accepted in revised form 25 May 2004.

\section{Household size}

The notation used to describe the so-called quantity parameter in REUM is $n$. The parameter $n$ is equal to the household size for most indoor end-uses. For the purpose of this investigation the household size is considered to be measured in units of people per household (PPH). In other words, it is the number of water consumers on the stand.

Many values for household size have been published. The 51 published values that could be obtained from the literature vary between 2.6 and 4.7 PPH for suburbs, with a typical value of approximately 3.3 PPH for South African suburbs.

As could be expected, the value is higher (and less predictable) for township stands, ranging from 3.8 to $8.2 \mathrm{PPH}$ for the seven published values obtained; no typical value is apparent. Up to 27 PPH have been reported (Simpson, 1983), but these higher values include more than one household, or tenants, on a single stand; such stands are not included in the present investigation.

It has been reported that per capita water use decreases substantially with an increase in the household size. The reduction in per capita water demand from 1 to $4 \mathrm{PPH}$, recorded in a detailed study by Edwards and Martin (1995), was about 40\%. This value pertains almost exclusively to indoor demand, because the reported outdoor demand represents less than $5 \%$ of the total. Morgan (1973) presents similar findings regarding reduced per capita water demand with an increase in the household size.

However, for the illustration of differences due to different WDM measures in this paper (which cannot affect the household size) it was decided to maintain a constant per capita demand.

\section{Blended water temperature}

The desired "hot" water temperature is a blend of hot and cold water, thus it is termed blended water temperature. The value appears to be linked to the human body temperature (about $38^{\circ} \mathrm{C}$ ). Relatively small variation around this value has been reported in 


\begin{tabular}{|c|c|c|c|}
\hline \multicolumn{4}{|c|}{$\begin{array}{c}\text { TABLE } 1 \\
\text { Description of parameters investigated }\end{array}$} \\
\hline \multirow[t]{2}{*}{ Aspect investigated } & \multicolumn{3}{|c|}{ Model adjustment required } \\
\hline & Description & Parameter & REUM notation \\
\hline \multicolumn{4}{|l|}{ General characteristics } \\
\hline All & Household size & Household size & d \\
\hline \multirow[t]{2}{*}{ Geographic Significance } & Monthly rainfall & Rainfall & $\mathrm{R}$ \\
\hline & Monthly pan evaporation & Evaporation & $\mathrm{p}$ \\
\hline Hot water demand & Desired hot water temperature & Blended temperature & $\mathrm{T}_{\mathrm{b}}$ \\
\hline \multicolumn{4}{|c|}{ WDM measure or adjustment } \\
\hline \multirow[t]{3}{*}{ Toilet retrofit } & Conventional toilet & Large flush volume & $\mathrm{b}_{\text {TOILET LARGE }}$ \\
\hline & Dual flush toilet & Large flush volume & $\mathrm{b}_{\text {TOLLET LARGE }}$ \\
\hline & Dual flush toilet & Small flush volume & $\mathrm{b}_{\text {TOLET SMALL }}$ \\
\hline \multirow[t]{2}{*}{ Shower retrofit } & Shower nozzle flow rate & Shower event volume & $\mathrm{b}_{\text {SHOWER }}$ \\
\hline & Shower duration & Shower event volume & $\mathrm{b}_{\text {SHOWER }}$ \\
\hline Pool & Pool evaporation & Pool cover use factor & $\mathrm{f}_{\text {POOL EVAPORATION }}$ \\
\hline Leaks & Per capita leaks & Leak volume & $\mathrm{b}_{\text {LEAKS }}$ \\
\hline \multirow[t]{2}{*}{ Washing machine } & Washing machine brand choice & Soluble substance mass & $\mathrm{t}_{\text {WASHING MACHINE }}$ \\
\hline & Retrofit washing machine & Event volume & $\mathrm{b}_{\text {WASHING MACHINE }}$ \\
\hline \multirow[t]{3}{*}{ Xeriscaping } & Vegetation type and crop factor & Crop factor & $\mathrm{k}_{\mathrm{m}, \text { VEGETATIONTYPE }}$ \\
\hline & Vegetation surface area & Surface area & $\mathrm{S}_{\text {VEGETATION TYPE }}$ \\
\hline & Garden Irrigation Factor & Garden irrigation factor & $\mathrm{f}_{\text {VEGETATIONTYPE }}$ \\
\hline
\end{tabular}

literature and measured by the authors, limited to a tolerance of less than $4^{\circ} \mathrm{C}$ above or below $38^{\circ} \mathrm{C}$.

\section{Leaks}

A discussion regarding water leaks in distribution systems, such as provided by McKenzie et al. (2002), is beyond the scope of this paper. So-called plumbing leaks, representing leaks on a stand downstream of the consumer's water meter, are termed "leaks" in this paper.

Lambert et al. (1999) suggests that a minimum night flow of $100 \mathrm{l} / \mathrm{stand} \cdot \mathrm{d}$ is an average performance for a system with typical pressure and density of service connections. DeOreo et al. (1996) report $27.4 \mathrm{l} / \mathrm{c} \cdot \mathrm{d}$ of leaks from a detailed study (i.e. $82.2 \mathrm{l} / \mathrm{stand} \cdot \mathrm{d}$ for a household size of $3 \mathrm{PPH})$. The latter value is used in this investigation as an illustrative example to represent leaks.

\section{Toilet flush volume}

A dual-flush toilet has a large and small flush volume, instead of only one volume for a flush event. Various types of dual-flush toilets are available. Comparative tests between two models were conducted by DeOreo et al. (2001) as part of a retrofit programme. In South Africa dual-flush toilets are relatively expensive and are not readily available. Dual-flush toilets commonly use 6 and $3 \mathrm{l/}$ flush, or 9 and 4.5 l/flush, for large and small flushes respectively.

Some argue that dual-flush toilets need to be flushed twice to effectively clear the pan. However, DeOreo et al. (2001) found that double flushing was not a problem with the dual-flush toilets used in their retrofit programme (the entire toilet comprising cistern and pan needs replacement to ensure that an effective flush is maintained during dual-flush operation).
When modelling dual-flush toilets the flush frequency has to be analysed by considering flush frequency for each of the large and small flush types independently. Butler (1991) found that 58\% of dual-flush toilet's flushes were small - for the purpose of this study a 60/40 ratio for small/large flush frequency of a dual-flush toilet is assumed.

The typical flush volume used in this investigation to model a conventional toilet is $14.3 \ell$ /flush. For a dual-flush toilet 6 and $3 \ell /$ flush are used as illustration in this paper for the large and small flush respectively.

\section{Shower event volume}

The event volume for the shower is determined by the flow rate of the nozzle multiplied by the duration of the shower event. Numerous literature references and measurements indicate that a low flow head discharges about $0.1 \mathrm{l} / \mathrm{s}$ while a high discharge would be about $0.3 \ell / \mathrm{s}$ (as high as $0.5 \mathrm{l} / \mathrm{s}$ has been reported). Typical shower duration is $300 \mathrm{~s}$, but this could vary significantly - normally between about $120 \mathrm{~s}$ and $820 \mathrm{~s}$.

The above values suggest $12 \ell /$ event and $246 \ell /$ event as the minimum and maximum shower event volumes respectively. However, lower and higher values than these have been reported in the literature for extreme events. The most typical shower event volume is considered to be $60 \mathrm{l} /$ event.

\section{Pool evaporation (pool cover use)}

Pool evaporation is dependent mainly upon the pool water surface area and evaporation (in REUM pool filtering is calculated separately and is unaffected by the use of a pool cover). Pool water surface area was found to vary between $12 \mathrm{~m}^{2}$ and $60 \mathrm{~m}^{2}$, with an 
average of $35 \mathrm{~m}^{2}$ per pool. When investigating a single residence the exact pool surface area could be entered into the model, but in order to compare the REUM results to actual water consumption of a larger number of homogeneous stands it would be necessary to appropriately reduce the pool size based on the actual number of residences with pools.

It was found that $38 \%$ of all respondents during a survey indicated the presence of a pool (Rand Water, 1998). Taking into account this fraction an average pool surface area for all stands is $13,3 \mathrm{~m}^{2}$ per stand. The lack of information for other geographical regions led to the adoption of the value for other areas as well.

In the case of a pool the parameter $f$ describes the efficiency of evaporation from the pool surface. Thus, no pool cover implies complete evaporation ( $f_{\text {POOL }}=1$ ), whereas the use of a pool cover implies that no evaporation can take place $\left(f_{P O O L}=0\right)$.

For the purpose of this study a "pool cover" is defined as any device that completely covers the entire pool surface area so as to prevent water from evaporating from the pool surface. Pool covers merely aimed at the safety of toddlers (such as net-type covers) have no effect on evaporation and are ignored.

\section{The brand of washing machine powder}

The soluble substance mass added at each end-use is modelled in REUM. The washing machine was chosen for illustrative purpose in this investigation.

Patterson (1999) reports a significantly different mass of soluble salts for 40 different brands of washing powder analysed in Australia. It is reported in that study that up to $40 \%$ of some products' mass is merely soluble salts used as industrial fillers with no active role during the washing process.

A similarly wide spread of values is apparent for different South African products analysed by the authors. Six washing machine powders tested produce significantly different results for the total mass of soluble substances. The range is $29870 \mathrm{mg}$ to $88430 \mathrm{mg}$ per single dosage (i.e. per end-use event). The chosen value for modelling a baseline scenario is $60000 \mathrm{mg}$ per dosage and represents the typical value of washing machine detergent powders.

Human habits regarding the addition of soluble substances to the wastewater stream cannot easily be determined, unless it is known which brand names' product is used at the stand (this normally varies over time).

\section{Vegetation type and crop factors}

The different methods for measurement of climatological parameters pertaining to evaporation and the subsequent methods for estimating pan and crop factors were compared by Sentelhas and Folegatti (2003). They point out that the conversion factors vary depending on site and weather conditions. For the purpose of this investigation, values for these factors published in the WRSM90 Appendices (Midgley et al., 1994) for different regions of the country are used. However, crop factors for lawn grass genotypes are not included in their work.

The water demand and crop factors for numerous lawn grass genotypes were investigated by Short and Colmer (1999) in Perth, Australia. Of all the various genotypes studied, Pennisetum glandestinum (kikuyu) was considered to be most applicable for lawns in South Africa, and subsequently the crop factor value for kikuyu was used for modelling lawns in this study.

Only a mid-summer crop factor value for each genotype is presented by the above authors, leaving the monthly distribution of the value unknown. In order to obtain such an estimate (12 monthly values are required as input to REUM) it was assumed that the crop factor for kikuyu is distributed monthly in the same manner as the crop factor for the vegetation type "Pure Grassveld", presented by Midgley et al. (1994). The latter authors also provide crop factors for various natural veld types - ones that could be used to estimate values for similar vegetation types in residential gardens.

\section{Vegetation surface area}

A parameter for stand size is not included directly in the structure of REUM. Instead, the irrigable areas of up to three different vegetation types have to be provided. In order to include the stand size as an independent variable in REUM it is thus necessary to obtain a relationship between total stand size and the irrigable area of the stand.

A cadastral stand layout superimposed on high resolution aerial photographs was used to estimate lawn sizes of a few stands in relation to the total stand size (such photos are available for many South African cities). A few additional stands were also physically inspected. Based on the analyses of 14 stands, the irrigable lawn size appears to vary between $20 \%$ and $30 \%$ of the total stand size in most cases, and the total irrigable (vegetated) garden area normally varies between $30 \%$ and $40 \%$ of the total. The smallest stand analysed had an area of $290 \mathrm{~m}^{2}$ and the largest $1944 \mathrm{~m}^{2}$.

Only residential stands smaller than $2000 \mathrm{~m}^{2}$ are considered in this paper. The main reason for this limitation includes the fact that - by far - most of the 600000 residential stands analysed as part of work by Jacobs et al. (2004), which is used for comparison, are smaller than $2000 \mathrm{~m}^{2}$.

Aerial photographs and -inspections suggest that a typical lowincome township stand has an insignificantly small vegetated area, if any. However, the stands are very small, often with scattered outbuildings and cars obscuring the potentially irrigated vegetation on such stands. Also, consumers in these areas are being encouraged by some to practice small-scale vegetable farming and horticulture for economic gain. Water managers should individually identify such consumers in order to ensure that an accurate estimate of their water use is used for demand forecasting and system analysis.

It was assumed for this investigation that the irrigable lawn area covers $25 \%$ of each stand and that garden beds cover an additional $13 \%$ of the area.

\section{Garden irrigation factor}

The garden irrigation factor $f$ can be adjusted to represent changes in the efficiency of the irrigation system and in the habits of consumers regarding over- or under-irrigation of vegetation. The parameter is directly related to over-irrigation and indirectly related to the efficiency of the irrigation system. The value of $f$ is arguably the most unpredictable of all the REUM inputs, while the garden water demand is the largest water demand contributor.

The value of $f$ could be considered to vary between 0 and some higher value. If it were assumed that the irrigation efficiency is relatively close to unity, the upper value of $\mathrm{f}$ is determined by overirrigation of vegetation (combined with the soil type). At some upper limit of water addition the plant will drown, because no oxygen can reach the roots.

Considering potential garden watering from boreholes and direct abstraction of groundwater by deep-rooted vegetation (such as trees) it could be expected that less than the ideal irrigation requirement of vegetation on a stand will have to be supplied by the 
TABLE 2

Results for each of the five REUMcomponents (Stand A, Johannesburg, $1000 \mathrm{~m}^{2}$ )

\begin{tabular}{|c|c|c|c|c|c|c|}
\hline \multirow[t]{2}{*}{ End-use } & \multirow{2}{*}{$\begin{array}{l}\text { AADD }_{\mathrm{i}} \\
(\mathrm{k} / \mathrm{d} \text { ) }\end{array}$} & \multirow{2}{*}{$\begin{array}{l}\text { AADD } \\
\text { (kl/d }\end{array}$} & \multirow{2}{*}{$\begin{array}{r}\operatorname{AADD}_{\mathrm{h}} \\
(\mathrm{k} \ell / \mathrm{d})\end{array}$} & \multirow{2}{*}{$\begin{array}{r}\text { AADF }_{w} \\
(k \ell / d)\end{array}$} & \multicolumn{2}{|c|}{ AADC $_{w}$} \\
\hline & & & & & $(g / d)$ & (mg/l) \\
\hline Bath & 0.061 & - & 0.031 & 0.061 & 3 & 46 \\
\hline Bathroom Basin & 0.041 & - & 0.020 & 0.041 & 35 & 842 \\
\hline Dishwasher & 0.019 & - & 0.000 & 0.019 & 22 & 1152 \\
\hline Kitchen sink & 0.040 & - & 0.020 & 0.040 & 12 & 299 \\
\hline Leaks & 0.082 & - & 0.000 & 0.074 & 0 & 0 \\
\hline Miscl. Indoor & 0.000 & - & 0.000 & 0.000 & 0 & 0 \\
\hline Shower & 0.055 & - & 0.027 & 0.055 & 4 & 66 \\
\hline Toilet Large & 0.159 & - & 0.000 & 0.159 & 505 & 3182 \\
\hline Toilet Small & - & - & - & - & - & - \\
\hline Washing Machine & 0.102 & - & 0.051 & 0.102 & 55 & 537 \\
\hline Miscl. Outdoor & - & 0.015 & 0.000 & 0.000 & 0 & 0 \\
\hline Pool Filtering & - & 0.026 & 0.000 & 0.000 & 0 & 0 \\
\hline Garden 1 (Lawn) & - & 0.212 & 0.000 & 0.000 & 0 & 0 \\
\hline Garden 2 (other) & - & 0.113 & 0.000 & 0.000 & 0 & 0 \\
\hline Garden 3 (other) & - & 0.000 & 0.000 & 0.000 & 0 & 0 \\
\hline Pool Evaporation & - & 0.054 & 0.000 & 0.000 & 0 & 0 \\
\hline TOTAL or AVERAGE & 0.559 & 0.420 & 0.150 & 0.551 & 635 & 1151 \\
\hline AADD : +AADD & $57 \%$ & $43 \%$ & $15 \%$ & $56 \%$ & - & - \\
\hline
\end{tabular}

municipal supply system. Although this has not been recorded, it is also safe to assume that most consumers do not water their lawns during winter, especially in those areas where frost is common. Thus, it is likely that $f<1.0$.

For the purpose of modelling the xeriscape WDM measures discussed in this paper each scenario is modelled with $f=0.5$ and $f=1.0$.

\section{Verification of model results}

\section{Single REUM result for a typical stand}

A typical suburban, residential stand was chosen to form the basis for the analyses in this paper. This stand would be the one described by the typical values presented in the companion paper for each REUM input parameter, with a few exceptions: The household size is $3 \mathrm{PPH}$, the garden irrigation factor is 0.5 and the stand size is $1000 \mathrm{~m}^{2}$. The climatological parameters pertain to Johannesburg and the garden beds are planted with vegetation having crop factors similar to that of "Tropical Bushveld" listed by Midgley et al. (1994). This baseline scenario is termed Stand A.

The results for Stand A are presented in Table 2, which includes the result for each of the five REUM components segregated by end-use. From left to right the columns represent the end-use, average annual daily water demand for indoor $\left(\mathrm{AADD}_{\mathrm{i}}\right)$, outdoor $\left(\mathrm{AADD}_{\mathrm{o}}\right)$ and hot water $\left(\mathrm{AADD}_{\mathrm{h}}\right)$, average annual daily flow of wastewater $\left(\mathrm{AADF}_{w}\right)$ and the average annual daily concentration of TDS in wastewater (AADC ${ }_{w}$ ).

The final column includes the actual mass of TDS added at each end-use to illustrate that the end-use responsible for the highest concentration of TDS in the wastewater is not necessarily the same as the one responsible for the highest mass of soluble substances added. This is apparent when comparing, for example, the values of the washing machine and the bathroom basin. The former obviously varies depending on the wastewater flow from each enduse - a relatively larger volume of wastewater from the end-use might dilute a large mass of soluble substances added at the same end-use.

\section{Total water demand}

With reference to Table 2, the total water demand for the stand is obtained by adding the indoor demand $\left(\mathrm{AADD}_{\mathrm{i}}\right)$ and outdoor demand $\left(A A D D_{o}\right)$, respectively $0.559 \mathrm{k} \ell / \mathrm{d}$ and $0.420 \mathrm{k} \ell / \mathrm{d}$. The total is $0.979 \mathrm{k} \ell / \mathrm{d}$. This result from the model correlates well with actual water demand estimates based on empirical guidelines presented by Jacobs et al. (2004) for the inland summer rainfall region of the country and suburban type stands. The empirical estimate for a stand of $1000 \mathrm{~m}^{2}$ (similar to Stand A) is $0.975 \mathrm{k} \ell / \mathrm{d}$, which is almost the same as the value predicted by REUM.

\section{Water demand by end-use}

The combined contribution by the toilet, bath-shower and washing machine is $67.4 \%$ of the indoor total calculated with REUM. This compares well with values reported in the literature for the combined contribution of these end-uses to the total indoor demand: 61 to $71 \%$ (Edwards and Martin, 1995), 59 to 88\% (Billings and Jones, 1996), 71 to 73\% (DeOreo et al., 1996), 67\% (Mayer et al., 1999), and 68\% (Ball et al., 2003).

The per capita water demand for a conventional toilet varies from $37.5 \mathrm{l} / \mathrm{c} \cdot \mathrm{d}$ (White et al., 1996) in Denmark to $113.6 \mathrm{l} / \mathrm{c} \cdot \mathrm{d}$ (Baumann et al., 1998) in the USA. Most values reported vary between 40 and $60 \mathrm{l} / \mathrm{c} \cdot \mathrm{d}$ (e.g. Edwards and Martin, 1995; DeOreo et al., 1996) and compare well with the REUM result of $52.9 \mathrm{l} / \mathrm{c} \cdot \mathrm{d}$.

The per capita water demand for a washing machine varies between $22.5 \ell / c \cdot d$ (Achttienribbe, 1998) and $79.5 \ell / c \cdot d(B a u m a n n$ et al., 1998), with the most detailed study reporting $30.5 \ell / c \cdot d$ 
(Edwards and Martin, 1995). REUM predicts $0.102 \mathrm{k} \ell / \mathrm{d}$ (a per capita demand of $34.1 \mathrm{l} / \mathrm{c} \cdot \mathrm{d}$ ), which agrees well with the latter value.

Values reported in literature for the per capita bath water demand vary from as low as $3.8 \mathrm{l} / \mathrm{c} \cdot \mathrm{d}$ to $163.0 \mathrm{\ell} / \mathrm{c} \cdot \mathrm{d}$. This is largely dependent on whether an individual prefers to bath or shower, both of which have the same purpose (cleaning the body). Values for the per capita shower water demand vary from $29.4 \mathrm{l} / \mathrm{c} \cdot \mathrm{d}$ (Achttienribbe, 1998) to $60.6 \mathrm{l} / \mathrm{c} \cdot \mathrm{d}$ (Tchobanoglous and Burton, 1991). REUM predicts $38.7 \mathrm{l} / \mathrm{c} \cdot \mathrm{d}$ for the bath and shower combined.

\section{Hot water demand}

Basson (1983) suggests a value of $50 \mathrm{l} / \mathrm{c} \cdot \mathrm{d}$ for the hot water demand for a developed community in South Africa. Based on measured results for 700 stands Meyer and Tshimankinda (1997) estimate that the average annual hot water demand for mediumdensity houses in South Africa is $59.3 \mathrm{l} / \mathrm{c} \cdot \mathrm{d}$. Medium-density houses are defined in that study as those with a density of about 2029 houses per $\mathrm{km}^{2}$. The household size is reported to be 3.8 PPH. These published values agree well with the average annual hot water demand of $0.150 \mathrm{k} \ell / \mathrm{d}(50 \ell / \mathrm{c} \cdot \mathrm{d})$ predicted by REUM for a similar type of stand.

The monthly variation in hot water demand is more pronounced according to the measurements by Meyer and Tshimankinda than predicted by REUM. The measured results indicate variation between 42 and $80 \mathrm{l} / \mathrm{c} \cdot \mathrm{d}$ for summer and winter respectively, while REUM predicts variation between 45 and $55 \mathrm{l} / \mathrm{c} \cdot \mathrm{d}$ respectively.

The under-prediction by REUM in winter is considered to be caused by seasonal consumer habits. For example, if larger shower and bath event volumes were applicable in winter than in summer, it would lead to an increased hot water demand in winter. However, all indoor REUM parameters are kept constant over the 12 month modelling period for the purpose of illustrating differences in this paper.

\section{Wastewater flow}

Per capita wastewater flow is reported by Tchobanoglous and Burton (1991) and Lott et al. (1999). The range of values for a single residence is 170 to $341 \mathrm{\ell} / \mathrm{c} \cdot \mathrm{d}$. The typical value from both authors is about $250 \mathrm{l} / \mathrm{c} \cdot \mathrm{d}$ for a suburban stand, but no indication is given of whether this includes leaks.

Three components for wastewater flow (domestic water use, leaks, and infiltration), based on actual measurements and subsequent system modelling, are presented for a high-income residential area in Alberton (GLS, 2001). The results indicate a wastewater flow of $0.617 \mathrm{k} \ell / \mathrm{stand} \cdot \mathrm{d}$ resulting from domestic water use plus $0.259 \mathrm{k} \ell / \mathrm{stand} \cdot \mathrm{d}$ resulting from leaks. The average household size for high income suburbs in Alberton is 3.5 PPH (Veck and Bill, 2000). Although the two dates cited above are not the same, the change in average household size over a one-year period is considered to be negligible. The per capita wastewater flow is thus calculated to be $0.176 \ell / \mathrm{c} \cdot \mathrm{d}$ with an additional $0.074 \ell / \mathrm{c} \cdot \mathrm{d}$ contributed by leaks.

REUM predicts a wastewater flow of $0.551 \mathrm{k} \ell / \mathrm{stand} \cdot \mathrm{d}$, or $0.184 \ell / c \cdot d$. If leaks were excluded the value reduces to $0.159 \ell / c \cdot d$. REUM underestimates the domestic component of wastewater flow by about $10 \%$ when compared to the Alberton data. The REUM result is on the lower end of the range when compared to the values from the USA and Australia.

\section{Wastewater salinity}

Table 2 shows that REUM predicts a total increase of $1151 \mathrm{mg} / \ell$ in the TDS concentration between the potable water supplied to a stand and the wastewater directly downstream of the stand. This salinity increase is caused by the addition of soluble substances at the stand. It would be ideal to compare this modelled salinity increase with actual measurements for the same area. However, little research has been conducted in this regard, thus limiting the available data. Results from measured data in Australia and Cape Town are used for comparison in this paper.

Chemical analyses of wastewater from 12 wastewater treatment plants in the Western Cape were obtained (KV3, 2003). The analyses included electrical conductivity (EC) values. The latter values, converted to TDS concentrations, vary between $274 \mathrm{mg} / \ell$ and $1482 \mathrm{mg} / \ell$. The corresponding average TDS concentration of potable supply water varies between 50 and $250 \mathrm{mg} / \ell$. A typical increase of about $728 \mathrm{mg} / \ell$ between the supply water and wastewater TDS concentration (received at the wastewater treatment plant) is noted, while the highest increase in concentration is $1432 \mathrm{mg} / \ell$.

Patterson (1994) reports TDS concentration for wastewater flow from 50 homes in Australia. The mean value is $940 \mathrm{mg} / \ell$, with a range of $335 \mathrm{mg} / \ell$ to $3350 \mathrm{mg} / \ell$. The average potable supply water TDS concentration reported by the same author is $186 \mathrm{mg} / \ell$. The increase in TDS concentration between supply water and wastewater is about $754 \mathrm{mg} / \ell$, but the value could be as high as $3164 \mathrm{mg} / \ell$ based on the above mentioned wastewater TDS range.

The increase of $1151 \mathrm{mg} / \ell$ predicted by REUM is higher than the reported increases of $728 \mathrm{mg} / \ell$ and $658 \mathrm{mg} / \ell$, as could be expected. REUM predicts the change in concentration between the points immediately upstream and downstream of a residential stand, which could be viewed as a pollution source. However, the salinity of wastewater reaching the treatment works would have been diluted by water infiltrating the sewer system downstream of the stand. However, modelling such infiltration falls beyond the scope of REUM.

\section{Seasonal variation}

Seasonal variation in water demand is a common characteristic of demand. Consultants often use peak monthly flow rates to design certain elements in a water supply system (such as treatment facilities). Such values vary between 1.2 and 1.6 times the average annual daily demand (AADD).

A seasonal pattern of water demand obtained from REUM is presented in Fig. 1. It distinguishes between hot and cold water to show how the hot water demand increases during the colder winter months. This cyclic pattern of hot water demand has been confirmed by previous studies. It is clear from Fig. 1 that the total water demand reaches a peak in the summer, with a peak month demand of 1.3 times the AADD.

\section{Variation of AADD by stand size and geographic region}

The influence of stand size and climatological effects on the AADD for a residential stand can be illustrated with REUM.

The water demand by stand size for stand $\mathrm{A}$ is presented in Fig. 2. The climatological parameters (rainfall, pan evaporation and cold water supply temperature) are varied to typify four geographic locations, namely Cape Town, George, Johannesburg and Windhoek.

The following is noted when comparing estimates based on the empirical guidelines by Jacobs et al. (2004) with REUM results for a stand size of $1000 \mathrm{~m}^{2}$ : 


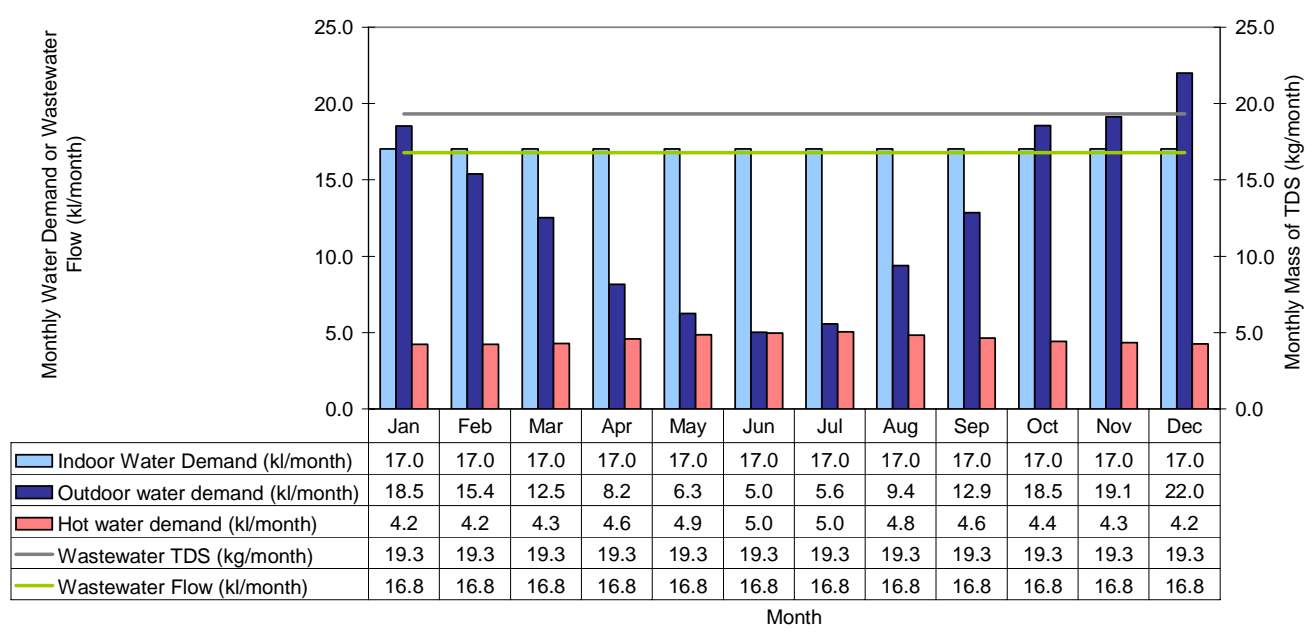

Figure 1

REUM results for all five components

Property: Stand A $\left(1000 \mathrm{~m}^{2}\right)$,

Johannesburg

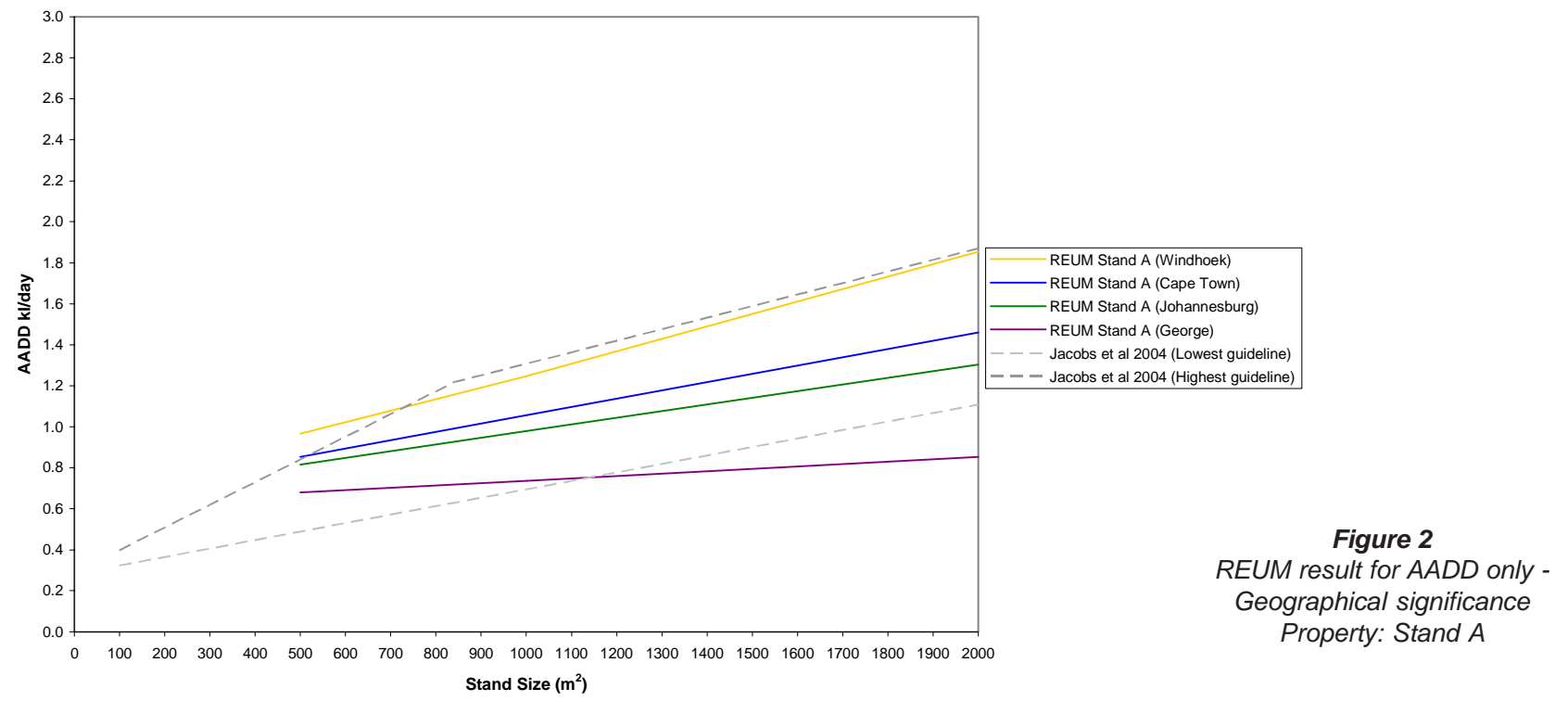

- Cape Town - the predicted result from empirical guidelines is $1.308 \mathrm{k} \ell / \mathrm{d}$. REUM predicts $1.056 \mathrm{k} \ell / \mathrm{d}$ and under-estimates the empirical value by $19 \%$. The most likely explanation is that home owners in Cape Town make less use of groundwater (e.g. via boreholes) than those in Johannesburg. If this were the case the value of the garden irrigation factor in REUM is too low for modelling garden water demand in Cape Town; the parameter was not adjusted to calibrate the model to the empirical estimates as part of this investigation.

- George - the REUM result is $0.737 \mathrm{k} \ell / \mathrm{stand} \cdot \mathrm{d}$ and is only $6 \%$ higher than the estimate based on the empirical guideline $(0.695 \mathrm{k} \ell /$ stand $\cdot \mathrm{d})$.

- Johannesburg - the result from empirical guidelines $(0.975 \mathrm{kl} /$ d) is almost the same as predicted by REUM $(0.979 \mathrm{k} \ell / \mathrm{d})$.

- Windhoek - the empirically estimated AADD is $1.080 \mathrm{k} \ell /$ stand $\mathrm{d}$, while the predicted AADD from REUM is $1.274 \mathrm{k} / /$ d. REUM over-estimates the water demand for Windhoek by about $15 \%$. This over-estimate could be expected and is considered to be due to the renowned WDM programme that is in place in Windhoek (water price is reported to play a major role).

The REUM result indicates that the water demand is lowest for George, and increases for Johannesburg, Cape Town and Windhoek in that order. The results for the modelled properties agree relatively well with the empirical guidelines, but the discrepancies for Cape Town and Windhoek show that model parameters describing human habits (e.g. actual garden irrigation volume versus theoretical garden irrigation requirements) cannot easily be populated and require further research.

\section{Variation of AADD by household size}

The water demand for varying stand size and household size is presented in Fig. 3. The results for the stand agree relatively well with the empirical envelopes presented by Jacobs et al. (2004).

The household size is varied from 1 to $4 \mathrm{PPH}$ (as discussed earlier in this paper, the per capita water demand is held constant). The graph clearly indicates that the water demand increases with stand size when the household size is held constant, and that an increased household size leads to an increased water demand. Figure 4 illustrates the impact of a change in household size on all five REUM components.

\section{Prediction of a few WDM measures' effects}

The above-mentioned results pertaining to the verification of the model as well as each WDM measure discussed in the following 


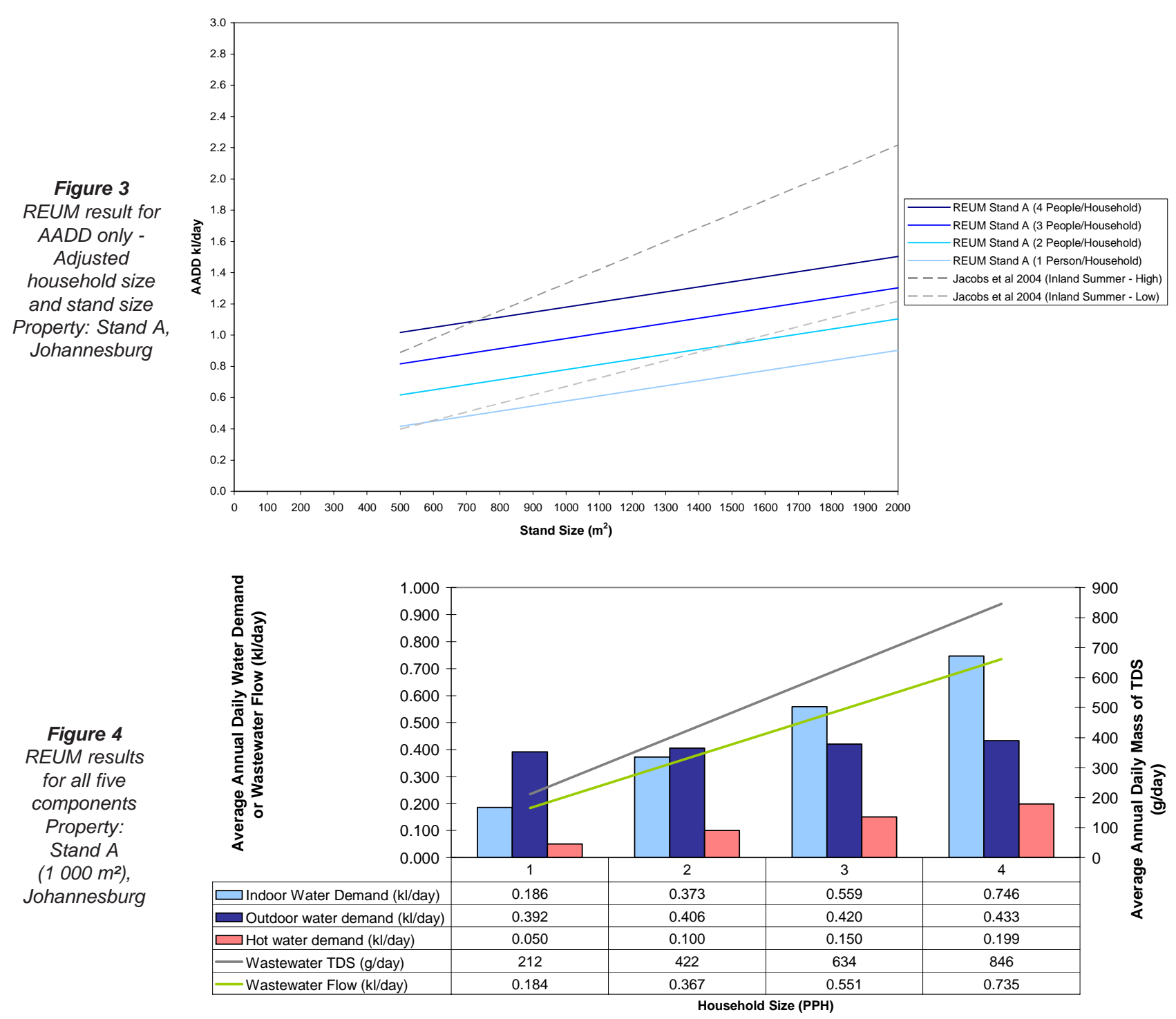

section of the paper are included in Table 3. The table structure is similar to Table 2, but instead of segregating each result by end-use only the annual average result for each REUM component is presented for each scenario. The segregation by end-use as presented in Table 2 is of course available from REUM in each case.

Table 4 lists the savings brought about by some of the WDM measures when compared to the baseline property (Stand A).

\section{Toilet retrofit}

The results for two alternative WDM measures regarding reduced toilet flush volume are included in Table 3 . The two alternatives are described by the following modelled properties:

- $\quad$ Stand B - retrofitting a 9.0 l/flush conventional toilet at Stand A where the pre-retrofit flush volume is $14.3 \ell /$ flush.

- Stand C - retrofitting a 6 to 3 l/flush dual-flush toilet at Stand A (note that such a low volume dual-flush system implies a complete toilet retrofit, including cistern and pan, to ensure efficient flushing).

As could be expected the savings included in Table 4 show that the dual-flush toilet provides an increased water saving and reduced waste water flow, but the TDS concentration is higher due to the reduced wastewater flow.

\section{Shower nozzle retrofit}

A reduced shower event volume can be obtained by retrofitting a $0.1 \mathrm{l} / \mathrm{s}$ low-flow showerhead at Stand A (the same reduction could be obtained by halving the shower duration while maintaining the pre-retrofit flow rate, which implies awareness and education of end-users):

- Stand D - a shower event volume of $30 \ell /$ event in place of 60 l/event for the pre-retrofit (Stand A).

Despite the use of this very low shower flow rate the water saving and impact on wastewater flow are not significant, but part of the reduced water demand is due to a saving in hot water.

\section{Pool presence and pool cover use}

As discussed earlier, the baseline property (Stand A) is modelled with a pool water surface area of $13.3 \mathrm{~m}^{2}$ in order to compare the results to empirical findings for whole neighbourhoods. Two 


\begin{tabular}{|c|c|c|c|c|}
\hline \multirow{11}{*}{ 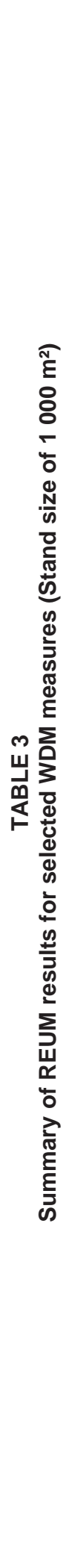 } & \multirow{2}{*}{ 证 } & 흥 & L & 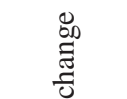 \\
\hline & & ชั & 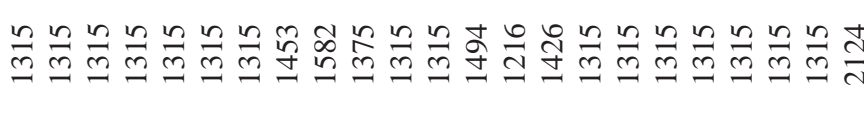 & \\
\hline & \multicolumn{2}{|c|}{ 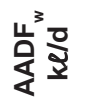 } & 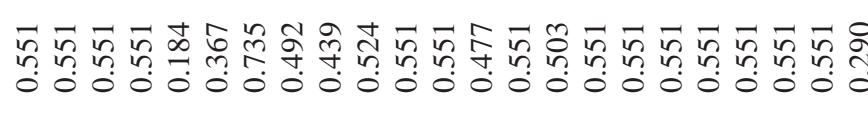 & 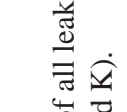 \\
\hline & \multicolumn{2}{|c|}{ 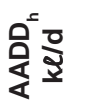 } & 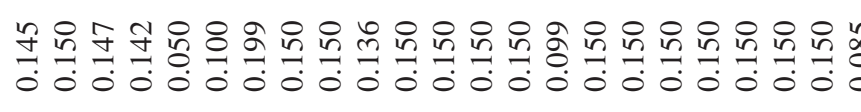 & 悹 \\
\hline & \multicolumn{2}{|c|}{ 产通 } & 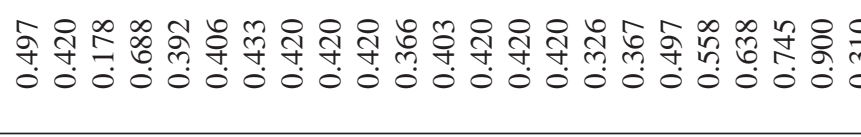 & 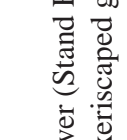 \\
\hline & \multicolumn{2}{|c|}{ 这 } & 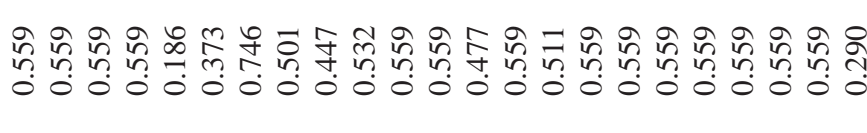 & $\begin{array}{l}0 \\
8 \\
0 \\
\pi \\
0\end{array}$ \\
\hline & \multicolumn{2}{|c|}{$\frac{0}{\frac{1}{4}}$} & 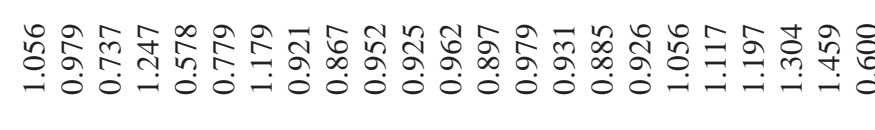 & 官泀 \\
\hline & \multicolumn{2}{|c|}{ 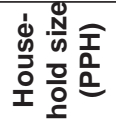 } & 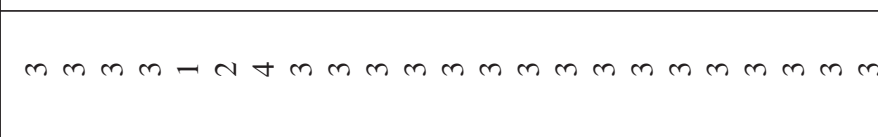 & \\
\hline & \multicolumn{2}{|l|}{ 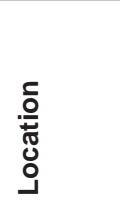 } & 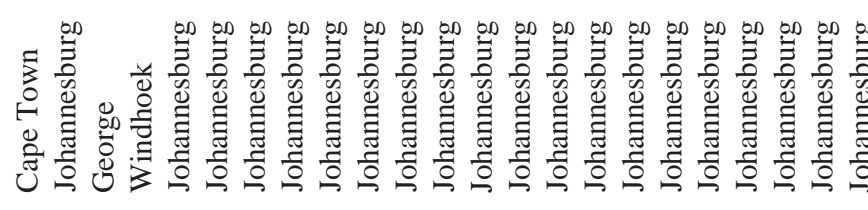 & $\frac{3}{0}$ \\
\hline & & 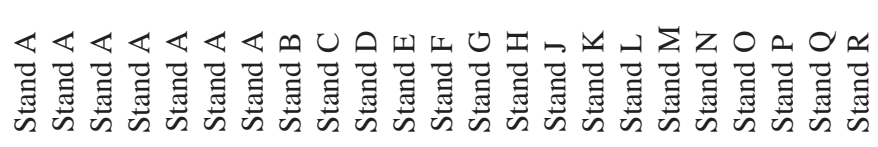 & 胥 \\
\hline & \multicolumn{2}{|l|}{. } & 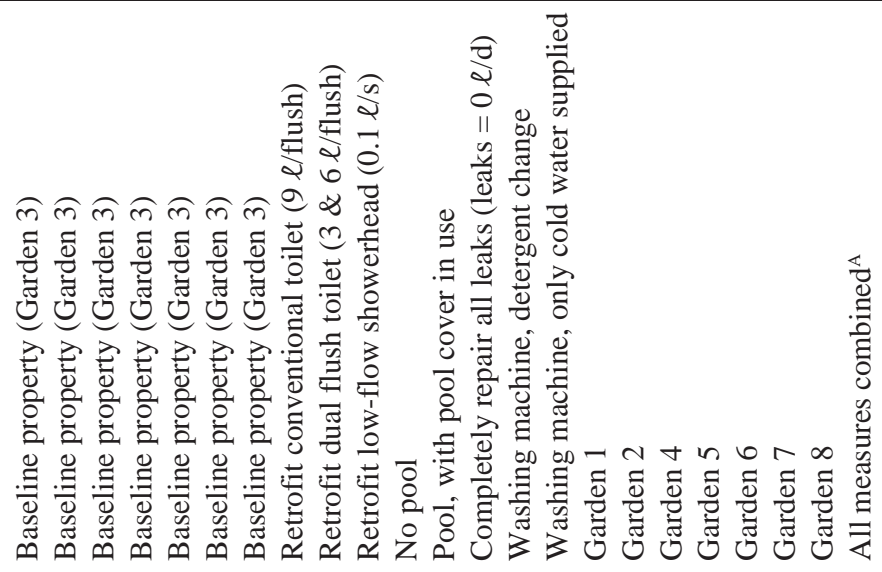 & 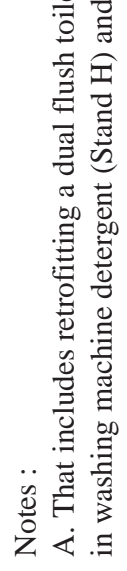 \\
\hline
\end{tabular}

alternatives are investigated to illustrate the effect of pools on the water demand and wastewater flow in a suburban neighbourhood:

- Stand E - describes complete absence of a pool (zero surface area).

- Stand F - describes the same pool as Stand $\mathrm{A}$, but a pool cover is used during the winter.

The model shows that a reduction of $1.7 \%$ brought about by the use of pool covers could be expected if all pools in a neighbourhood were to use pool covers during winter. This reduction is not significant, mainly because relatively few homes have pools. Also, it is noted that pool cover use does not impact hot water demand, wastewater flow or wastewater salinity.

However, when a consumer similar to Stand A, but with a large pool (say surface area $60 \mathrm{~m}^{2}$ ) is modelled separately, it is found that the use of a pool cover during winter leads to a water saving of about $9 \%$, which is substantial. The saving resulting from pool cover use varies from one geographical region to another, because it is dependent upon evaporation - the variation is significant. As an example, if the above stand were located in George a saving of only $3 \%$ would be obtained, while in Windhoek the saving would be $12 \%$.

\section{Repair of leaks}

An example is included in this investigation to illustrate the impact of leaks on the five REUM components. The leaks are adjusted as follows: 


\begin{tabular}{|c|c|c|c|c|c|c|c|}
\hline \multicolumn{8}{|c|}{$\begin{array}{c}\text { TABLE } 4 \\
\text { Savings due to WDM measures (Johannesburg, } 3 \text { PPH) }\end{array}$} \\
\hline Description & Scenario & $\begin{array}{r}\text { AADD } \\
\mathrm{k} \ell / \mathrm{d}\end{array}$ & $\begin{array}{c}\operatorname{AADD}_{i} \\
\mathrm{k} \ell / \mathrm{d}\end{array}$ & $\begin{array}{l}\text { AADD。 } \\
\mathrm{k} \ell / \mathrm{d}\end{array}$ & $\begin{array}{c}\operatorname{AADD}_{h} \\
\mathrm{k} \ell / \mathrm{d}\end{array}$ & $\begin{array}{l}\operatorname{AADF}_{w} \\
k \ell / d\end{array}$ & $\begin{array}{c}\text { AADC }_{\mathrm{w}} \\
\text { g/l }\end{array}$ \\
\hline Baseline property (Garden 3) & Stand A & 0.979 & 0.559 & 0.420 & 0.150 & 0.551 & 1315 \\
\hline \multicolumn{8}{|c|}{$\%$ Saving obtained with WDM measure on baseline property (a negative value indicates an increase) } \\
\hline Description & Scenario & \multicolumn{6}{|c|}{ \% Saving } \\
\hline Retrofit conventional toilet (9 l/flush) & Stand B & 5.9 & 10.4 & 0.0 & 0.0 & 10.7 & -10.5 \\
\hline Retrofit dual flush toilet (3 \& 6 l/flush) & Stand C & 11.4 & 20.0 & 0.0 & 0.0 & 20.3 & -20.3 \\
\hline Retrofit low-flow showerhead $(0.1 \ell / \mathrm{s})$ & Stand D & 2.8 & 4.8 & 0.0 & 9.3 & 4.9 & -4.5 \\
\hline No pool & Stand E & 5.5 & 0.0 & 12.9 & 0.0 & 0.0 & 0.0 \\
\hline Pool, with pool cover in use & Stand F & 1.7 & 0.0 & 4.0 & 0.0 & 0.0 & 0.0 \\
\hline Completely repair all leaks & Stand G & 8.4 & 14.7 & 0.0 & 0.0 & 13.4 & -13.6 \\
\hline Washing machine, detergent change & Stand $\mathrm{H}$ & 0.0 & 0.0 & 0.0 & 0.0 & 0.0 & 7.6 \\
\hline Washing machine, only cold water supplied & Stand J & 4.9 & 8.6 & 0.0 & 34.0 & 8.7 & -8.4 \\
\hline Garden 1 (25\% smaller lawn \& $50 \%$ less beds) & Stand K & 9.6 & 0.0 & 22.4 & 0.0 & 0.0 & 0.0 \\
\hline Garden 2 (25\% smaller lawn) & Stand L & 5.4 & 0.0 & 12.6 & 0.0 & 0.0 & 0.0 \\
\hline Garden 4 (adjust to high water use beds) & Stand $\mathrm{M}$ & -7.9 & 0.0 & -18.3 & 0.0 & 0.0 & 0.0 \\
\hline Garden 5 (as for Stand $\mathrm{K}$, but $\mathrm{f}=1.0$ ) & Stand N & -14.1 & 0.0 & -32.9 & 0.0 & 0.0 & 0.0 \\
\hline Garden 6 (as for Stand L, but $\mathrm{f}=1.0$ ) & Stand O & -22.3 & 0.0 & -51.9 & 0.0 & 0.0 & 0.0 \\
\hline Garden 7 (as for Stand A, but $\mathrm{f}=1.0$ ) & Stand P & -33.2 & 0.0 & -77.4 & 0.0 & 0.0 & 0.0 \\
\hline Garden 8 (as for Stand M, but $\mathrm{f}=1.0$ ) & Stand Q & -49.0 & 0.0 & -114.3 & 0.0 & 0.0 & 0.0 \\
\hline \multirow[t]{3}{*}{ All measures combined } & Stand R & 38.7 & 48.1 & 26.2 & 43.3 & 47.4 & -61.5 \\
\hline & Maximum & 38.7 & 48.1 & 26.2 & 43.3 & 47.4 & 7.6 \\
\hline & Minimum & -49.0 & 0.0 & -114.3 & 0.0 & 0.0 & -61.5 \\
\hline
\end{tabular}

- Stand G describes complete repair of all leaks by setting the parameter for leak volume equal to zero.

The results included in Table 4 illustrate that the repair of leaks impacts indoor water demand, wastewater flow and wastewater TDS concentration (hot water leaks are not modelled in REUM, neither are pressure variations).

\section{Washing machine retrofit and detergent change}

The effect of two changes at the washing machine is illustrated by modelling the following properties:

- Stand $\mathrm{H}$ - detergent change from an average mass of soluble substances (60 $000 \mathrm{mg} /$ event, as included in Stand A) to a very low mass (100 mg/event);

- Stand $J$ - a reduced event volume obtained by retrofitting the $114 \ell$ /event washing machine (which is the average event volume based on a survey) with a $60 \mathrm{l} /$ event machine (which is considered to be a minimum value for a modern machine) and connecting it only to the cold water supply.

The topic regarding hot vs. cold water use for clothes washing appears to be hotly debated, even by laymen. A brief survey, including 59 respondents, was conducted as part of another investigation. The aim of the survey was to:

- Establish whether it is practical to suggest that automated washing machine users wash clothes in cold water instead of hot water.
- Establish whether washing machines connect to the geyser supply, or heat water internally.

The results reflect individuals from suburban stands and the upper portion of the socio-economic profile. It is clear from both the consumer survey and a corresponding detergent study that cold water washing in automated washing machines is common in South Africa, with approximately $70 \%$ of washes being only in cold water. It is also clear from the survey that most machines (approximately $60 \%$ of the survey group) connect to the geyser supply as a source of hot water instead of heating water internally. It should also be noted that each detergent has an optimum temperature band within which it operates most effectively.

The savings summarized in Table 4 show that the detergent change reduces the wastewater TDS concentration by $7.6 \%$ and does not impact any other component of the model.

The retrofit of a new low-water use washing machine results in a low water saving of $4.9 \%$, but a substantial hot water saving of $34.0 \%$. The corresponding wastewater flow reduction is $8.7 \%$, which leads to an $8.4 \%$ increase in wastewater TDS concentration.

The hot water and subsequent energy savings are only relevant if the machine is assumed to not heat the water internally, in other words cold water is used for washing instead of hot water.

\section{Xeriscaping}

Xeriscaping originates from the Greek word xeri - meaning dry. The definition provided by Colorado Springs Utilities (CSU, 2001) is, "an attractive, sustainable landscape that conserves water and is 

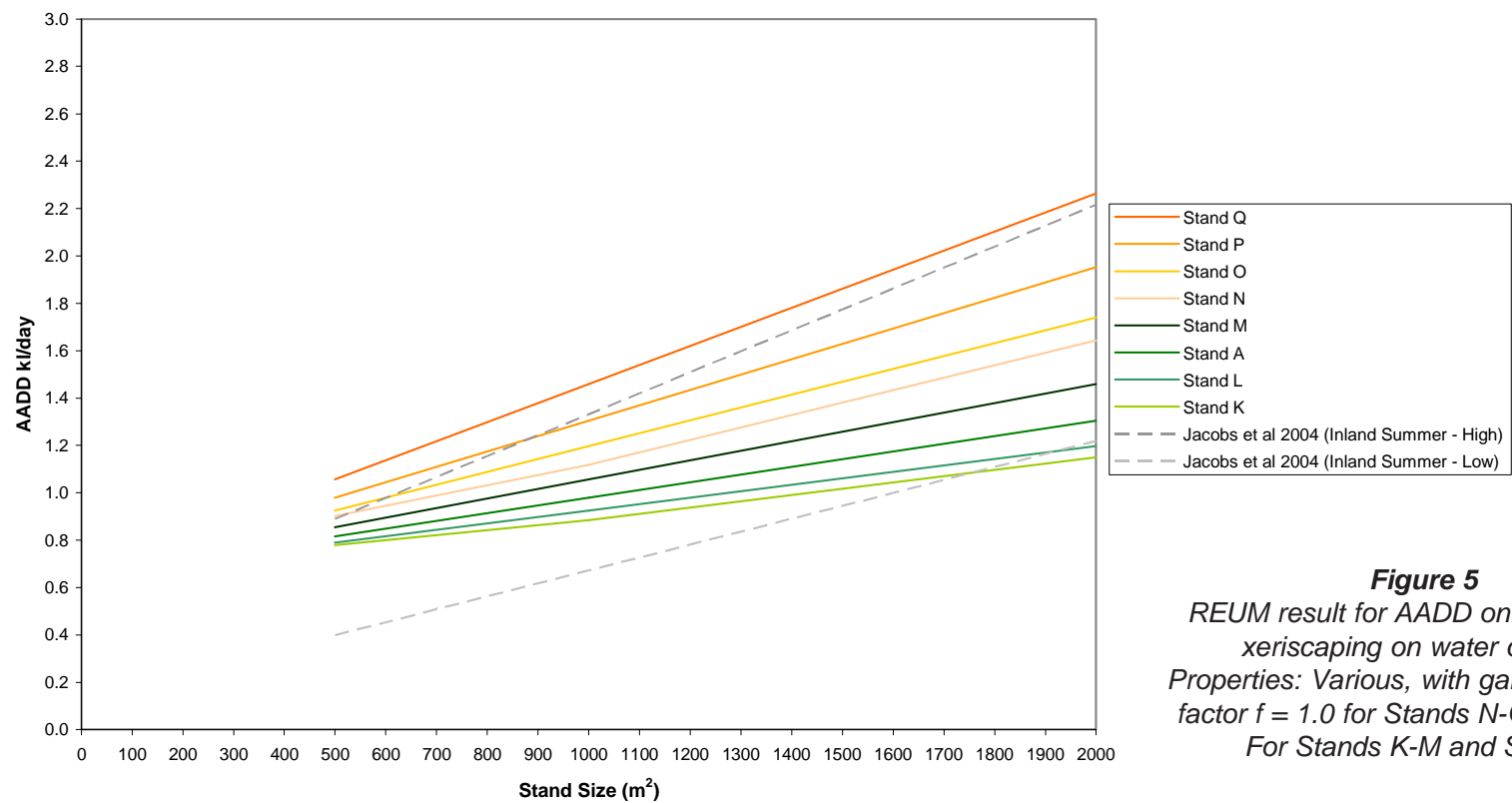

based on sound horticultural principles". Seven so-called xeriscape principles are listed by CSU: plan and design comprehensively, evaluate soil and improve if necessary, create practical lawn areas, use appropriate plants and group plants according to water needs, water efficiently, use organic mulches, and practice appropriate maintenance.

The key elements of any xeriscape programme provided by Wasowski (2001) include:

- The use of native plant genotypes

- The reduction of lawn area

- Water saving techniques, such as more efficient irrigation systems and mulching.

In order to investigate the effect of xeriscaping on water demand, two key elements of a xeriscape programme are identified and each is evaluated by means of adjusting selected parameters in REUM. The two elements comprise the use of alternative vegetation genotypes and changing the vegetated area.

The garden of the baseline property (Stand A) consists of $250 \mathrm{~m}^{2}$ kikuyu lawn plus $130 \mathrm{~m}^{2}$ garden beds with vegetation similar to natural veld type "Tropical Bushveld" presented by Midgley et al. (1994). Seven alternative garden scenarios are investigated:

- Stand K - a comprehensively xeriscaped garden with $25 \%$ reduced lawn size and $50 \%$ reduced garden beds. It is considered realistic that such reductions could be obtained by boldly implementing xeriscape practices.

- Stand $\mathrm{L}-$ a partly xeriscaped garden where the lawn size is reduced by $25 \%$.

- Stand M - A garden more luscious than the baseline stand, where garden bed vegetation type is replaced by "tropical forest” type vegetation.

- Stand N - as for Stand K, but the garden irrigation factor is equal to unity.

- Stand $\mathrm{O}$ - as for Stand L, but the garden irrigation factor is equal to unity.

- Stand $\mathrm{P}$-as for Stand A, but the garden irrigation factor is equal to unity.
- Stand Q - as for Stand M, but the garden irrigation factor is equal to unity.

A change in garden type impacts only on the water demand of the stand. The hot water demand, wastewater flow and wastewater TDS concentration are unaffected by these changes. For this reason the results of the AADD only are plotted against stand size in Fig. 5. Gardening practice has not been taken into account.

The result illustrates that the vegetation genotype has a significant impact on the water demand of a residential stand, and that it has an effect on the slope of the line when AADD is plotted against stand size. The results in Fig. 5 are compared to empirical curves (Jacobs et al., 2004). The variation neatly covers the entire spectrum between the empirical envelope curves.

It should be recalled that all the REUM results presented in Fig. 5 are based on $n=3 \mathrm{PPH}$, understandably leading to a convergence at the upper envelope around the $500 \mathrm{~m}^{2}$ stand size, where the demand is greatly driven by the indoor component.

The corresponding savings for the alternative garden scenarios are summarised in Table 4 . The change in water demand brought about by the different scenarios varies from a saving of $9.6 \%$ to an increase of $49.0 \%$ when compared to the baseline property. A saving of $39.3 \%$ could be obtained if the baseline stand were the one with the highest garden water demand (Stand Q). In agreement with this Hunt et al. (1998) report that xeriscaping could reduce water demand at a stand by as much as $50 \%$.

Plenty of other combinations of xeriscape scenarios could also be investigated with REUM.

\section{All measures combined}

The total impact of a few of the above-mentioned measures is evaluated by combining them as follows:

- Stand R - the combined implementation of the following: Retrofitting a dual-flush toilet (Stand C) and low-flow showerhead (Stand D), use of a pool cover (Stand F), the repair of all leaks (Stand G), a change in washing machine detergent (Stand $\mathrm{H}$ ), retrofitting the washing machine and limiting its supply to cold water(Stand J) plus a comprehensively xeriscaped garden (Stand K). 
The total impact of these combined measures on all 5 REUM components is significant.

A significant saving of $38.7 \%$ on the water demand of the baseline property (Stand $\mathrm{A}$ ) is achieved by implementing these measures. It should be noted that Stand A is modelled with a relatively low garden water demand when compared to some of the other garden scenarios.

A saving of $43.3 \%$ on hot water demand can be achieved by retrofitting the showerhead with a low flow nozzle and using only cold water supply for the washing machine (i.e. wash clothes in cold water instead of hot water). This would result in additional saving of energy as well.

The wastewater flow is predicted to reduce by $47.4 \%$ if these measures were implemented. This is contributed mainly by the reduced flow from the toilet, leaks and the washing machine.

An integral and significant increase of $61.5 \%$ is predicted by REUM for the TDS concentration in wastewater. This increase occurs despite the fact that Stand $\mathrm{R}$ includes a smaller mass of soluble substances in the washing machine detergent.

\section{Calibration options}

A “manual” heuristic approach implying trial and error adjustment of each REUM input parameter value, within reasonable limits, could be applied to manually calibrate REUM to measured results. However, the applicability of more comprehensive methods, such as a detailed deterministic approach and genetic algorithms, could be investigated as well in future.

\section{Further work}

REUM is a tool that encourages further work and opens up numerous possibilities for research in the water demand and wastewater fields. Further work could include:

- Sensitivity analysis of all parameters with the development of an index to measure the "importance" of each parameter

- Measurement of actual results for all 5 components as well as the REUM input parameters in order to calibrate the model to actual results

- Stochastic investigation into different WDM measures by means of Monte Carlo simulation - distribution functions could be established for each REUM input parameter

- Investigation of the reuse potential and the use of hot water demand to estimate reuse potential

- Consumer education regarding the use of more "friendly" household products (containing less soluble substances)

- Continued investigation into the TDS addition at each end-use - with the wide ranges recorded it is very difficult to deliver reliable results for the wastewater salinity, unless the human habits pertaining to TDS addition are well described

- The effect of human behavioural patterns on water demand for gardening, showering and clothes washing as well as TDS addition at each end-use

- The number of end-use appliances in homes for different living standard measurement (LSM) groups

- Continued investigation into leaks (i.e. so-called plumbing leaks)

- Continued investigation into garden water demand, with particular reference to crop factors for vegetation in gardens on residential properties

- Continued investigation into monthly rainfall and temperature to also evaluate long-term climatic changes in different regions of the country

\section{Conclusion}

The number of people per household is a strong driving force for indoor water demand, while for suburban stands with irrigated gardens moisture deficit (effective rainfall minus evaporation) is a strong driving force for outdoor water demand.

REUM indicates that a large number of parameters influence water demand, hot water demand, waste water flow and waste water TDS concentration, but that it is possible to estimate values for each of these parameters and apply the end-use concept practically. Future calibration of the model would further increase the accuracy and subsequently lead to wider practical application. Discrepancies between model results and empirical data are ascribed to the fact that unpredictable and varying human habits are not easily converted to parameters, which are required as inputs to the model - this is particularly relevant when predicting garden water demand.

Two key elements of xeriscaping were investigated and the results indicate that plant genotypes have significant impact on outdoor (and total) water demand. Xeriscaping is an option that clearly holds promise for water saving from the viewpoint of WDM.

Retrofitting a good quality dual-flush toilet significantly reduces water demand, but a corresponding significant increase in the wastewater TDS concentration is noted. In South Africa dualflush toilets are not yet a common commodity, while in the UK it was reported (Grant and Howarth, 2003) that almost $80 \%$ of all toilet sales are of the dual flush type. The need to double-flush was not noted to be a problem for dual-flush toilet types tested in other studies in Western countries, which are considered to be comparable to suburban type stands in South Africa. Retrofitting dual-flush toilets is considered to be more appropriate for suburban households, while a reduced flush frequency is more appropriate for township-type stands (where retrofitting dual-flush toilets often proves ineffective).

The installation of a low-flow showerhead leads to a reduction in water demand, hot water demand and wastewater flow. Obviously the advantage obtained depends on the habits of the particular household.

The WDM measures discussed in this paper go hand-in-hand with a mindset change, which is brought about by education, training and by means of example from educated consumers. Also, many of these appliances are not readily available in South Africa at present, but an increased demand for these products is likely to change this scenario in future.

The examples illustrated in this paper show the powerful nature of an end-use model. REUM is a cost-effective (free) tool for evaluation of WDM measures' effect on water demand and wastewater pertaining to a specific stand and a particular geographic location, described by a fixed set of input parameters. Hitherto untried WDM measures could also be evaluated by adjusting model parameters for a hypothetic device.

The structure proposed for REUM, and the practical application thereof, could be integrated into existing software packages for water demand and system analysis in order to extend the flexibility and applicability of such packages.

\section{References}

ACHTTIENRIBBE GE (1998) Water price, price elasticity and the demand for drinking water. J. Water Sci. Technol. 47 (4)196-198.

BALL A, STYLES M, STIMSON K and KOWALSKI M (2003) Measuring microcomponents for demand forecasting. In: Maksimovic C, 
Butler D and Mermon FA (eds.)Advances in Water Supply and Management. Swets \& Zeitlinger, Lisse. 673-680.

BASSON J A (1983) Die Verwarming van Huishoudelike Water. National Building Research Institute, CSIR Report, Pretoria.

BAUMANN DD, BOLAND JJ and HANNEMAN WM (1998). Urban Water Demand Management and Planning. Published by McGrawHill, 1998.

BILLINGS RB and JONES CV (1996) Forecasting Urban Water Demand. Published by AWWA.

BUTLER D (1991)A small-scale study of wastewater discharges from domestic appliances. Water Environ. Manage. J. 5 (4)178-185.

CSU (2001) The Seven Principles of Xeriscape. From the Colorado Springs Utilities website: www.csu.org.

DeOREO WB, DIETEMAN A, SKEEL T, MAYER PW, LEWIS, DM and SMITH J (2001) Retrofit realities. J. Am. Waste Water Assoc. 3 58-72.

DeOREO W B, HEANEY JP and MAYER PW (1996) Flow trace analysis to assess water use. J. Am. Waste Water Assoc. 1 79-90.

EDWARDS K and MARTIN L (1995) A methodology for surveying domestic water consumption. Water Environ. Manage. J. 9 477-488.

GRANT N and HOWARTH D (2003) The economics of water efficient products in the household. In: Maksimovic C, Butler D and Mermon FA (eds.) Advances in Water Supply and Management. Swets \& Zeitlinger, Lisse. 581-589.

GLS (2001) Computer Analysis and Master Planning of Sewerage System. Volume 1 Report by Geustyn Loubser Streicher Civil Consulting Engineers. March.

HUNT JB, McDEVITT W and HUNT G (1998) Water Efficiency Manual for Commercial, Industrial and Institutional Facilities. A joint publication of the Division of Pollution Prevention and Environmental Assistance and Division of Water Resources of the North Carolina Department of Environment and Natural Resources, and the Land-ofSky Regional Council, August 1998.

JACOBS HE (2004) A Conceptual End-use Model for Residential Water Demand and Return Flow. Ph.D. Thesis, Rand Afrikaans University, Department of Civil Engineering. April.

JACOBS HE, GEUSTYN LC, LOUBSER BF and VAN DER MERWE B (2004) Personal communication regarding article "Estimating residential water demand in Southern Africa" submitted for publication in J. S. Afr. Inst. of Civ. Eng.

JACOBS HE and HAARHOFF J (2004) Structure and data requirements of an end-use model or residential water demand and return flow. Water SA 30 (3)

KV3 (2003) Personal communication. Kwezi V3 Consulting Engineers, Civil Engineering Division, Bellville. October.

LAMBERT AO, BROWN TG, TAKIZAWA M and WEIMER D (1999) A review of performance indicators for real losses from water supply systems. J. Water Sci. Technol. 48 (6) 227-237.

LOTT S, PATTERSON RA and PETROV R (1999) On-Site Systems Soils, Salts and Solutes. Proc. On-Site '99 Conf.: Making On-Site Wastewater Systems Work. University of New England, Armidale. 1315 July.
YER PW (1999) Residential End-Uses of Water. AWWA Research Foundation Study.

NZIE RS, LAMBERT JN and KOCH JE (2002) Development of a Simple and Pragmatic Approach to Benchmarking Real Losses in Potable Water Distribution Systems in South Africa (Benchleak User Guide). Water Research Commission Report No TT 159/01.

MEYER JP and TSHIMANKINDA M (1997) Domestic hot-water consumption in South African houses for developed and developing communities. Int. J. Energy Res. 21 667-673.

MORGAN WD (1973) Residential water demand: The case from micro data. Water Resour. Res. 9 (4) 1065-1067.

MIDGLEY DC, PITMAN WV and MIDDLETON BJ (1994) Surface Water Resources of South Africa. Report Appendices 298/1.1/94 to 298/5.1/94, compiled for the Water Research Commission by the University of the Witwatersrand.

PATTERSON RA (1999) Reuse initiatives start in the supermarket. New South Wales Country Convention. Institution of Engineers Australia. Northern Group. 6-8 Aug.

PATTERSON RA (1994) On-Site Treatment and Disposal of Septic Tank Effluent. Ph.D. Thesis. Departments of Resource Engineering and Agronomy and Soil Science, University of New England Armidale, August 1994.

RAND WATER (1998) Rand Water Consumer Survey: Survey on Attitudes and Perceptions on Water Use - Suburbs. Report EG01, Rand Water Marketing Department.

RAND WATER (1996) Rand Water Annual Report 1996. Rand Water.

SENTELHAS PC and FOLEGATTI MV (2003) Class A pan coefficients to estimate daily reference evapotranspiration. Revista Brasileira de Engenharia Agricola e Ambiental. 7 (1) 111-115.

SHORT D and COLMER T (1999) Update of Western-Australia Water Use Study: A Comparison of Eleven Turf Grass Genotypes During Summer in Perth. University of Western Australia.November.

SIMPSON GC (1999) Research into the Effects of Reduced Water Consumption on Domestic Sewer Systems. WRC Report No 199/1/92.

TCHOBANOGLOUS G and BURTON FL (1991) Wastewater Engineering: Treatment, Disposal and Reuse ( $3^{\text {rd }}$ edn.). Metcalf and Eddy Inc. Published by McGraw-Hill.

VAN ZYL JE, HAARHOFF J and HUSSELMAN ML (2003) Potential application of end-use demand modelling in South Africa. J. S. Afr. Inst. of Civ. Eng. 45 (2).

VECK GA and BILL MR (2000) Estimation of the Residential Price Elasticity of Demand for Water by Means of a Contingent Evaluation Approach. WRC Report 790/1/00.

WASOWSKI A (2001) Changing the American landscape. J. Am. Waste Water Assoc. 3 40-44.

WHITE S, VAN DER ZWAN JT and WYATT RW (1996) International report. Water demand management and conservation including water losses control. Proc. 20 th Int. Water Supply Assoc. Congress and Exhibition: Water Supply. pp 5-1 to 5-42. 